\title{
Experimental Study of Surface Deformation and Flow Pattern On Buoyant-Thermocapillary Convection
}

Free surface deformation is one of the most important physical phenomena in fluids with free surface. In the present paper, convection and surface deformation caused by thermocapillary effect in a rectangular cavity were investigated. In ground experiments, the convection was also affected by gravity. The cavity has a horizontal cross section of $52 \mathrm{~mm} \times 42 \mathrm{~mm}$ and the thikkness of the liquid layer is $4 \mathrm{~mm}$. Temperature difference between two sides of the liquid layer was increased gradually, and the flow in liquid layer will develop from steady to unstable convection. An optical diagnostic system consisting of a revised Michelson interferometer with image processor was developed to study fluid surface deformation in convection, and the displacements of free surface oscillation were determined. PIV technique was adopted to observe the evolution of flow pattern, and the velocity fields were obtained quantitatively. The present experiments demonstrate that surface deformation is quite distinct in buoyant-thermocapillary convection. in order to understand the mechanism of buoyant-thermocapillary convection, not only the hydrothermal wave instability but also the surface wave instability should be discussed.

\section{Introduction}

Thermal capillary convection is driven by the non-uniformity of surface tension caused by non-uniform surface temperature. It is an important convection phenomenon for many applications, such as crystal growth and film science etc. The convection driven by surface tension brings about the deformation of the surface, and then forms a return-flow due to mass conservation. According to fluid mechanics, there will occur a shear flow near

Mail address:

*Q. Kang, National Microgravity Laboratory/CAS; Institute of Mechanics, Chinese Academy of Sciences, Beijing 100080, China.

E-mail: kq@imech.ac.cn

Paper submitted: 01.10.2002

Submission of final revised version: 10.11.2003

Paper accepted: 12.11 .2003 the free surface, which is liable to cause oscillation or introduce instability. In theoretical studies on the mechanism of capillary convection oscillation, one approach is to study the hydrothermal wave obtained in metabolic free surface ${ }^{[1]}$; another is to study the surface wave obtained in metabolic free surface ${ }^{[2]}$. The hydrothermal wave has been observed extensively, and the its instability has also been discussed and analyzed [1-3]. Surface deformation normally accompanies thermal capillary convection, and surface wave will occur on free surface when the convection develops into an oscillatory convection. Surface wave is one of the characteristics in flow transition ${ }^{[4]}$. It is important to study surface deformation and surface wave in thermal capillary convection for understanding the mechanism of thermal capillary convection. In recent years, the measurements of surface waves in floating half zones have been carried out by optical methods ${ }^{[5-7]}$, and the surface wave characteristics of thermal capillary convection are studied by theoretical analyses ${ }^{[8]}$.

In the discussion of actual systems with thermal capillary convection, thermal transfer is an important factor. The coupling of the thermal transfer and the convection driven by surface tension gradients is a basic characteristic. In ground experiments, gravity effects can not be completely neglected. The fluid flow is the coupling of thermal capillary convection and buoyancy convection. It is generally called buoyant-thermocapillary convection.

In the present experiment, optical interference techniques are introduced to measure surface deformation of the fluid layer in a rectangular cavity. The optical diagnostic system consists of a revised Michelson interferometer, which has a higher measurement sensitivity in comparison with conventional experimental methods, and a newly developed image processing unit for the study of the interference fringe pictures. By combining this optical method with the PIV (particle image velocimetry) technique, not only were the surface deformation and surface wave observed, but also the velocity fields of buoyant-thermocapillary convection were measured. Optical interferometer and PIV technique have been proved to be convenient measurement methods for studying fluid flows. The present experiment also 
demonstrates that surface deformation and surface wave are very significant physical phenomena in buoyant-thermocapillary convection.

\section{The experiment model}

Figure 1 shows a schematic diagram of the experimental facilities. The horizontal section of the test container is rectangular with a cross-section of $52 \mathrm{~mm} \times 42 \mathrm{~mm}$. The two longer lateral walls are made of transparent K9 optic glass for flow visualization and PIV application. The thickness of the K9 glass is $6 \mathrm{~mm}$. The two shorter lateral walls are made of copperplates, which are also $6 \mathrm{~mm}$ in thickness. The copperplate in the right side of the cavity was heated by a Electro-thermal film. And a Eurotherm 904 Type controller was used to control the heating rate. The temperature of the copperplate in the left side of the cavity was controlled at a constant temperature by a semiconductor cooling sheet and radiator. Temperature differences between the two copperplates will be measured by a T type thermocouple. The adiabatic bottom of the cavity is made of insulation materials, whose surface barely reflects laser light. In the present experiment, FC-70 liquid was used, and the temperature difference between the two copperplates was increased at a

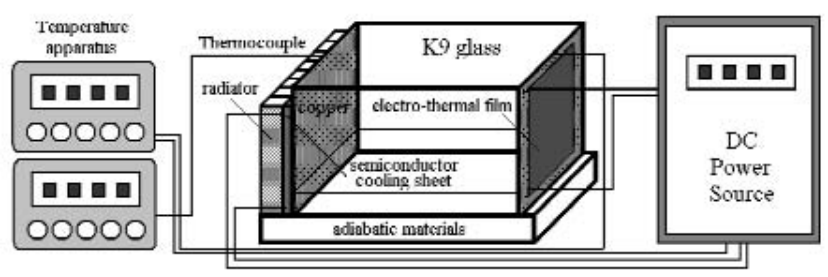

Fig. 1: Schematic diagram of the experiment facilities

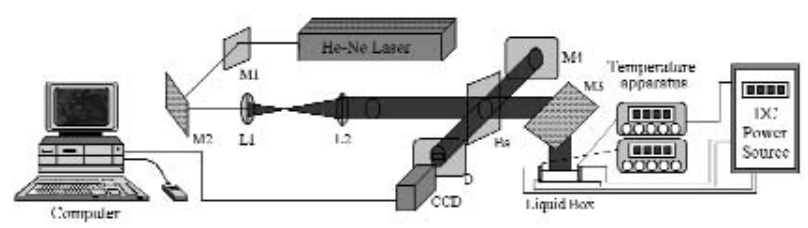

Fig. 2 Optical interference system

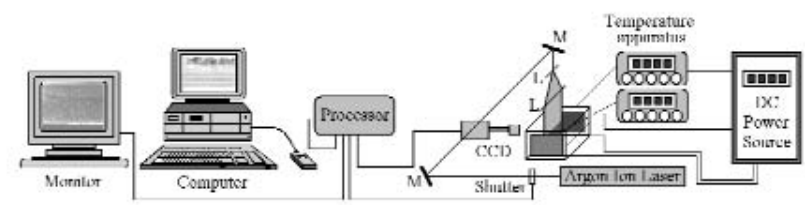

Fig. 3 Arrangement of the PIV in the experiment constant speed of $0.0075^{\circ} \mathrm{C} / \mathrm{sec}$. The fluid flow will develop from steady convection into unsteady convection with increasing of temperature difference between two sides of fluid layer. In order to analyze the relationship and the mechanism between convection, surface deformation and/or surface wave, the optical interference method and the PIV technique were used simultaneously to measure the free surface deformation of the fluid and the $2 \mathrm{D}$ velocity field in a vertical cross-section.

\section{Diagnostic Method}

The optical interference method is a promising technique for measuring mini variations of physical attributes. It is normally used to measure surface deformation in Solid Mechanics, and has recently been used to measure temperature, density and concentration fields in fluids. No disturbance on the measured object is one of its most prominent characteristics. However, the optical interference method has rarely been used to observe fluid surface deformation. In the present experiment, efforts were made to apply the Michelson interference method to measure the surface shape of a fluid, the variation of which is on the order of microns. Figure 2 shows the diagram of the optical diagnostic system. A He-Ne laser passes through lens L1 and L2 to form an expanded parallel light beam, and it is then split by splitter Bs into two parallel light beams. One is object light beam, and the other is the reference light beam. The object light beam is projected to the liquid surface vertically, and is reflected by the free surface of liquid. Mirror M4 is used to reflect the reference light. Finally, the object beam and the reference beam meet on the splitter Bs and then project together on a ground glass D. Thus, an interferometric fringes pattern forms on the ground glass D, which carries the information of surface deformation caused by the buoyant-thermocapillary convection. The fringe pattern is finally captured by a CCD camera and is recor-

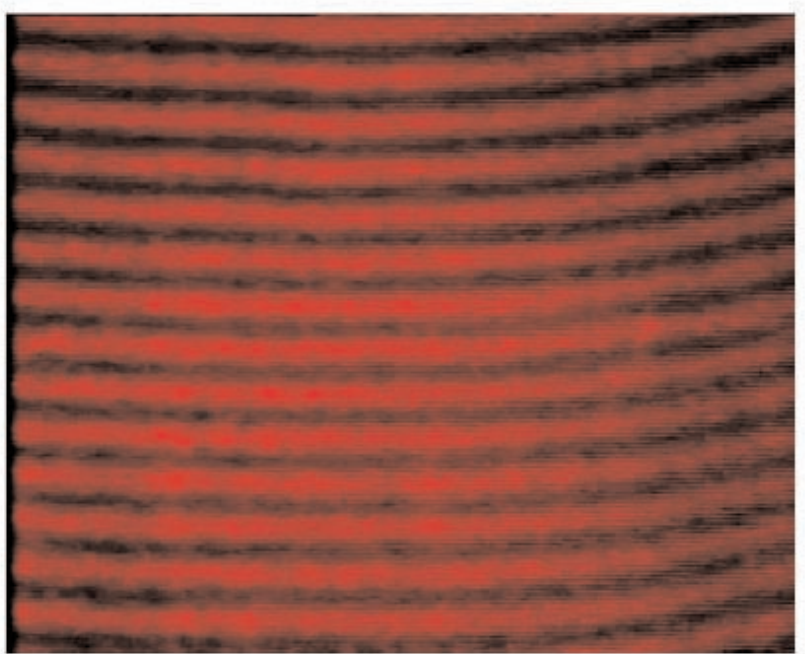

Fig. 4 Interference fringe pattern at temperature difference $0^{\circ}$ 
ded directly by a computer with the help of an image-capture card of the DVR Station. Correlative software is developed to obtain relevant surface shape from the interferometric fringes pattern. In the present experiment, the viewing field of interferometer is $20 \mathrm{~mm} \times 16 \mathrm{~mm}$, which is at the center part of the cavity. Because of the soakage effect of FC-70, the liquid surface near the side of the cavity is acclivitous, and is outside the measurement range of interferometer.

In order to calculate the surface deformation from the interference fringe images, a grating analysis is proposed. The fringe pattern at a temperature difference of $0^{\circ} \mathrm{C}$ is used as the original grating; and the fringe pattern at the other temperature difference is used as the metamorphic grating. Phase distributions of the original grating and the metamorphic grating are calculated as follows. First, Fourier transformations are used to transform the two gratings to their frequency domains. Second, phase images are calculated by the abstract of the first level of frequency spectrums and inverse Fourier transformations, and the wrapped phases image are then unwrapped. Thirdly, subtract the original phase grating from the phase of the metamorphic grating, the resultant is the phase difference distribution, which is introduced by the surface deformation. Finally, according to the relationship between the fringe phase difference $\Delta \Phi$ and the vertical displacement $\Delta z(\Delta \Phi=4 \pi \Delta z / \lambda, \lambda$ laser wave length $)$, the surface deformation could be calculated ${ }^{[9,10]}$.

In order to study the relationship between the surface deformation and the temperature oscillation, a T type thermocouple was inserted into the liquid layer to measure temperature change with time. In addition, the PIV technique was applied to measure the velocity distribution of the flow field. A system of Digital Particle Image Velocimetry (DPIV) with a Flow Map PIV 2000 Processor, manufactured by DANTEC measurement technology $\mathrm{A} / \mathrm{S}$, was adopted to quantitatively measure the 2-D velocity field in a vertical cross-section of the liquid layer, as shown in Figure 3. An argon ion laser illuminates the flow field. Illumination pulses were controlled by an electro-optical shutter, which was controlled by a center processor with CCD camera synchronization. The resolution of CCD camera is 768 x 484 pixels with $11.6 \times 13.6 \mu \mathrm{m}$ pixel pitch. The tracer particles suspending in the liquid layer are aluminum powder spheres of $10 \mu \mathrm{m}$ diameter. By means of a cycling lens, a light sheet of less than $1.0 \mathrm{~mm}$ thickness is produced to illuminate a vertical crosssection at the center part of the cavity along the longer walls. The cross-correlation technique of DPIV image matching processing was used to obtain both the magnitude and direction of the velocity vector.

\section{Experimental Results}

In the present experiment, the thickness of FC-70 liquid layer is $4 \mathrm{~mm}$ in the test cavity. Temperature difference between two opposite sides of the cavity increased from $0^{\circ} \mathrm{C}$ to $30^{\circ} \mathrm{C}$ at the rate of $0.0075^{\circ} \mathrm{C} / \mathrm{sec}$. Fig. 4 shows a interference fringe pattern at the temperature difference $0^{\circ} \mathrm{C}$. Fig. 5 shows the evolution of interference fringe patterns with the increase of temperature difference. Fig. 6 displays the evolution of the surface deformation calculated from the corresponding interference pattern shown in Fig. 5. In these figures, the right side is heated, and the left side is cooled. While the temperature difference between the heated and cooled two sides is very small, the surface at the cooled side will be a little higher than that at heated side, because the liquid on the free surface is pulled from the heating side to the cooling side by a thermocapillary force. At this time interference fringes will tilt as shown in Fig. 5(a-b), and the corresponding surface shapes are shown in Fig. 6(a-b). When the temperature difference is between $9.9^{\circ} \mathrm{C}$ and $13.2^{\circ} \mathrm{C}$, a flexural surface shape occurs as shown in Fig. 6(c-e). The corresponding temperature oscillation is shown in Fig. 7. The frequency and amplitude of temperature oscillation are $0.23 \mathrm{~Hz}$ and $0.03^{\circ} \mathrm{C}$ respectively. In the present experiment, inerratic temperature oscillations occur only when the temperature difference is between $9.9^{\circ} \mathrm{C}$ and $13.2^{\circ} \mathrm{C}$. We believe that the surface curve is caused by the non-

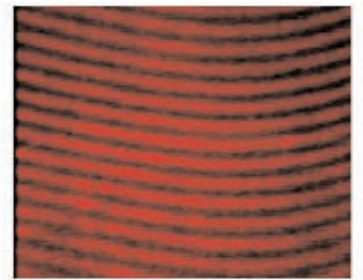

(a) $\quad 1 T=5.6^{\circ} \mathrm{C}$

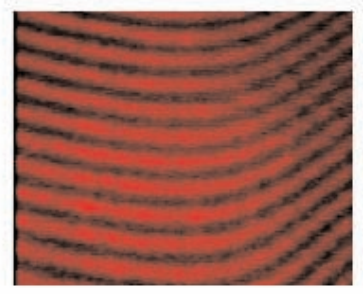

(c) $\Delta 7^{\circ}=9.9^{\circ} \mathrm{C}$

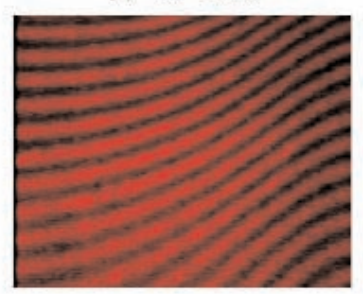

(c) $\quad \Delta T=13,1^{\circ} \mathrm{C}$

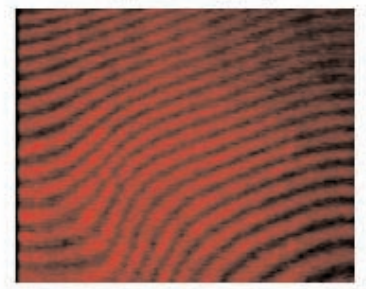

(g) $17 \quad 22.0^{\circ} \mathrm{C}$

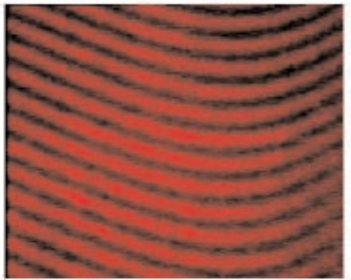

(b) $1 T=8.0^{\circ} \mathrm{C}$

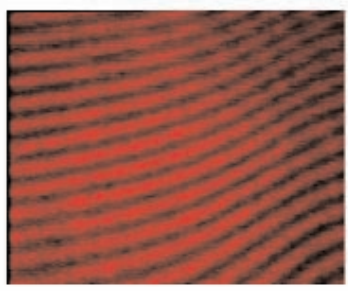

(d) $\Delta 7=11.8^{\circ} \mathrm{C}$

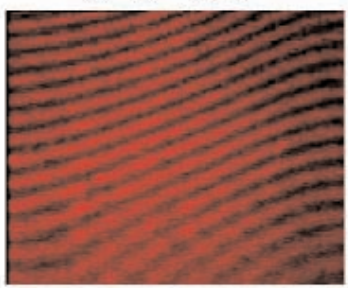

(f) $\quad \Delta T=14,2^{\circ} \mathrm{C}$

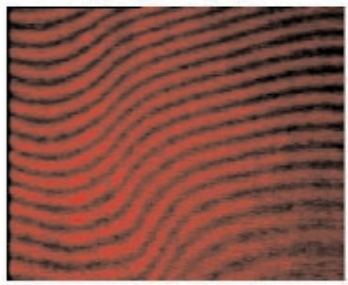

(h) $17 \quad 233^{\circ} \mathrm{C}$
Fig. 5: The evolution of interference fringe patterns for a free liquid surface 


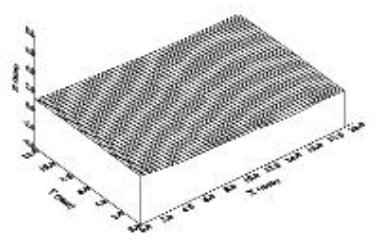

(a) $\Delta T \quad 5.6^{\circ} \mathrm{O}$

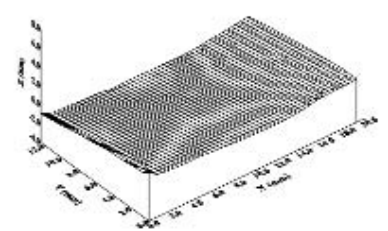

(c) $1 T=9.9^{\circ} \mathrm{C}$

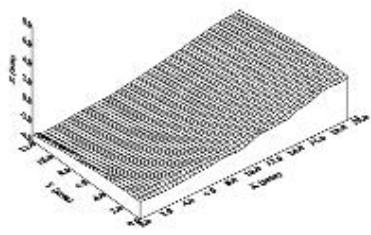

(e) $\Delta T \quad 13.1^{\prime \prime} \mathrm{C}$

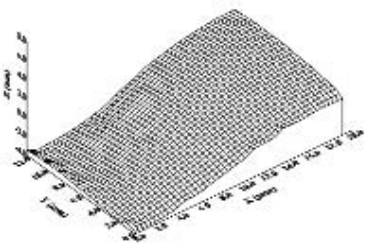

(g) $\quad \Delta T-22.0^{\circ} \mathrm{C}$

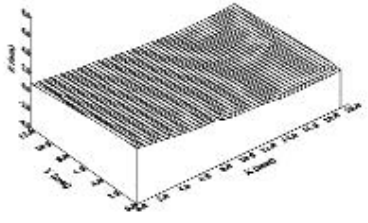

(b) $4 T \quad 8.0^{\circ} \mathrm{C}$

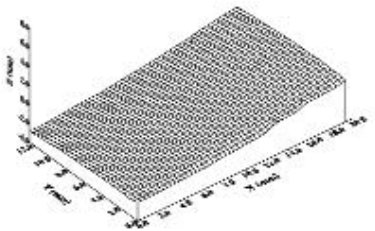

(d) $\quad A T=11.8^{\circ} \mathrm{C}$

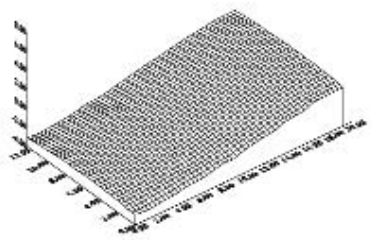

(1) $\Delta T \quad 14.2^{\circ} \mathrm{C}$

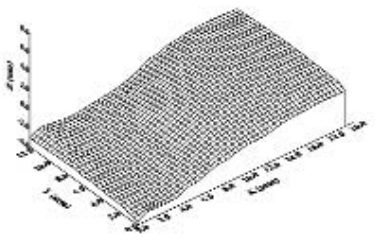

(h) $\quad 4 T-23.3^{\circ} \mathrm{C}$
Fig. 6 The evolution of surface deformation calculated from the interference fringe pattern

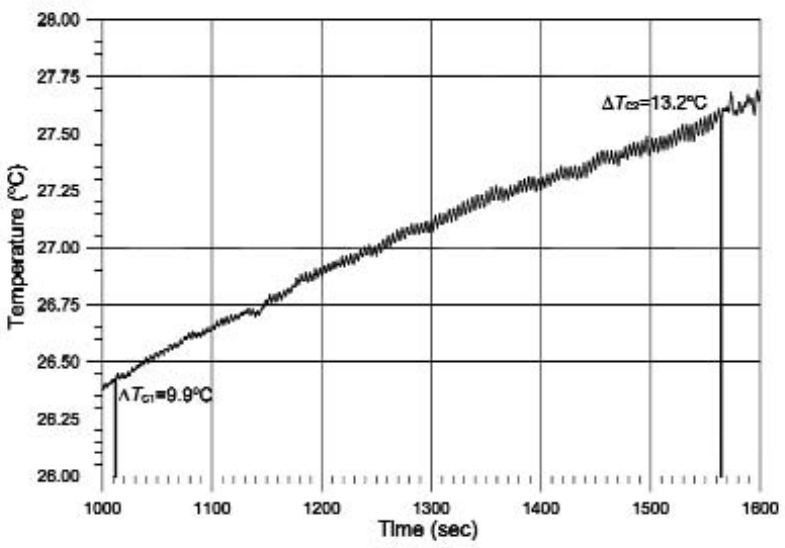

Fig. 7 The profile of temperature oscillation uniformity of temperature gradient on the free surface, the intensification of convection and the buoyancy effect near the heated and the cooled sides. When the temperature difference is larger than $20^{\circ} \mathrm{C}$, the experiments show that interference fringes firstly bend seriously at the heating side, and then the curving part of fringes moves gradually to the cooling side as shown in Fig. 5(g-h). It demonstrates that a wave crest appears at the heating side and moves gradually to the cooling side as shown in Fig. 6(g-h), and then another wave crest appears at the heating side. The period of the surface wave is about 5.5 seconds, and the wave amplitude is about $2 \mu \mathrm{m}$.

In the Micro-PIV system, a light sheet of $0.8 \mathrm{~mm}$ thickness is projected into the fluid vertically to illuminate a center crosssection of liquid along the direction of temperature gradient. The cross-section of the measured area in the present experiment is $6.2 \mathrm{~mm} \times 4 \mathrm{~mm}$ located in the middle of the cavity. Fig. 8 shows the evolution of flow patterns as long as the temperature difference $\Delta T$ is less than its critical value $\Delta T_{\mathrm{cl}}$, which is the temperature difference for the onset of temperature induced oscillation. The experimental results demonstrate that the convection is steady in this range. The fluid near the free surface flows from the heating side to the cooling side, and then turns back to the heating side from the lower layer. Fig. 9 shows a group of evolutional flow patterns when temperature difference $\Delta T$ is much larger than the critical temperature difference $\Delta T_{\mathrm{c} 1}$. Several vortexes appear in the upper layer of the liquid, and move gradually from the heating side to the cooling side. Unsteady convection occurs within this range. Furthermore, the rotary directions of all vortexes are uniform, which is quite different from that of Bénard-Marangoni Convection.

The effect of the intensity of buoyancy forces relative to that of thermocapillary force on convection can be quantified in terms of dynamic Bond number $B o^{[1]}$,

$$
B o=\frac{\rho g \beta d^{2}}{\gamma}
$$

Where $\rho$ is the density of fluid, $g$ is the gravitational acceleration, $\beta$ is the thermal expansion coefficient, $\gamma$ is the negative change rate of surface tension with temperature, and $d$ is the depth of the liquid layer. According to the thermal physics property of FC-70 as shown in Table 1 and the present experiment conditions, the dynamic Bond number $B o$ will be 2.53, that is to say, buoyancy forces will have non-negligible effect on the convection $^{[11]}$. The driving force for buoyancy convection is the

\begin{tabular}{|c|c|c|c|c|c|}
\hline$\rho$ & $\beta$ & $\gamma$ & $v$ & $\kappa$ & $d$ \\
$\left(\mathrm{gcm}^{-3}\right)$ & $\begin{array}{c}\gamma \\
\left(\mathrm{K}^{-1}\right)\end{array}$ & $\left(\mathrm{Dycm}^{-1} \mathrm{~K}^{-1}\right)$ & $\left(\mathrm{cm}^{2} \mathrm{~s}^{-1}\right)$ & $\left(\mathrm{cm}^{2} \mathrm{~s}^{-1}\right)$ & $(\mathrm{cm})$ \\
\hline 1.94 & $1.00 \times 10^{-3}$ & 0.120 & 0.134 & $3.44 \times 10^{-4}$ & 0.4 \\
\hline
\end{tabular}

Table 1 The physical properties of FC-70 


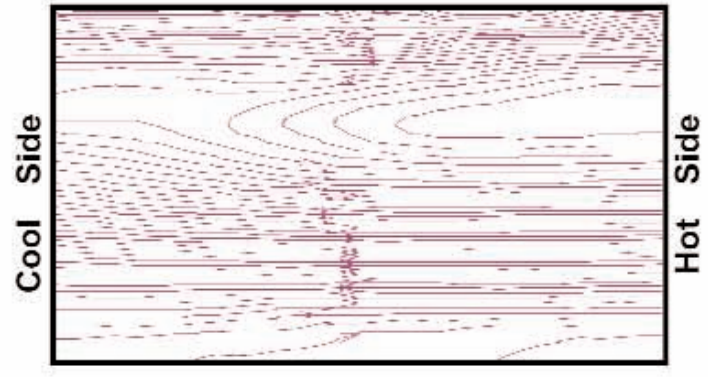

(a) $\mathrm{t}=0.000 \mathrm{sec}$

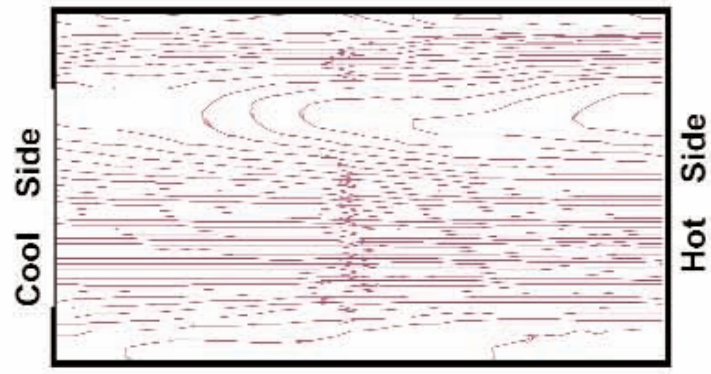

(c) $\mathrm{t}=0.666 \mathrm{sec}$

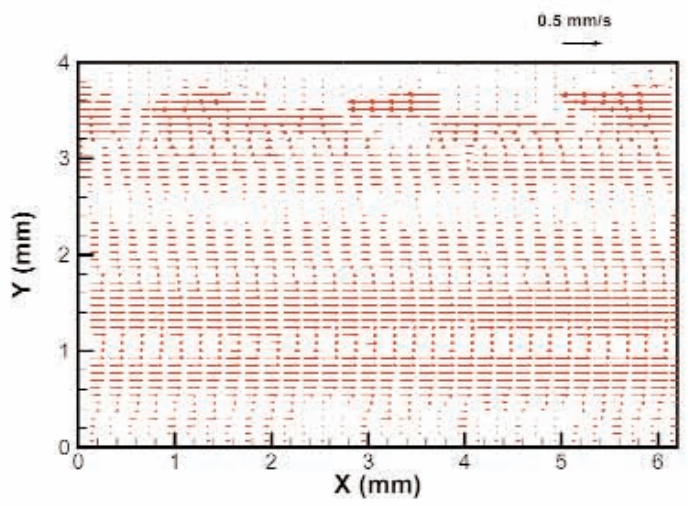

(e) $\mathrm{t}=0.000 \mathrm{sec}$

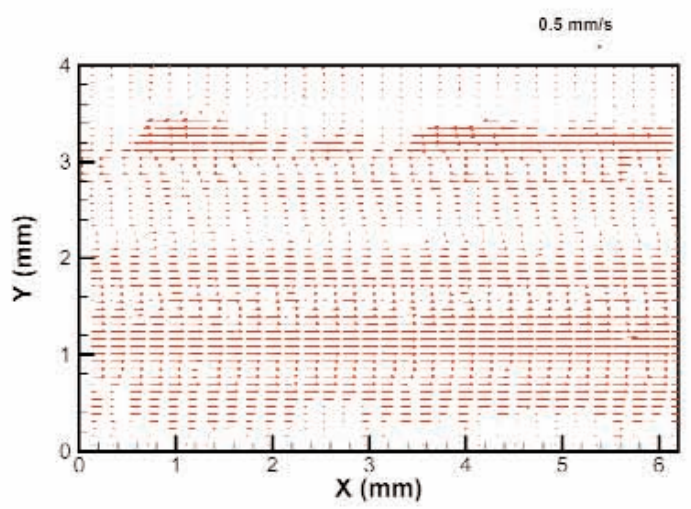

(g) $\mathrm{t}=0.666 \mathrm{sec}$

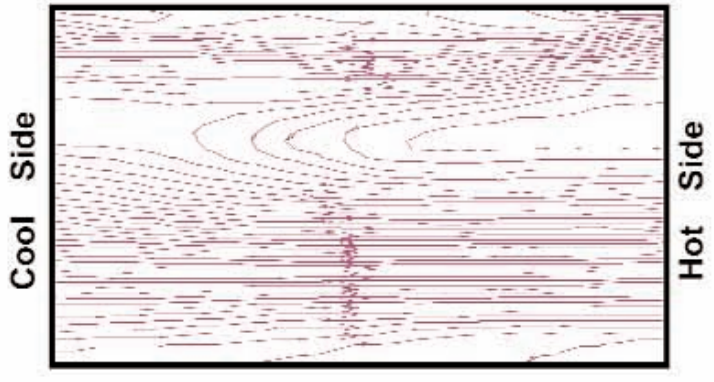

(b) $\mathrm{t}=0.333 \mathrm{sec}$

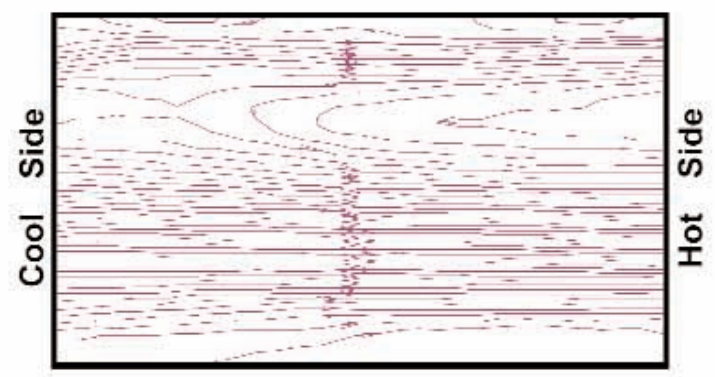

(d) $\mathrm{t}=1.000 \mathrm{sec}$

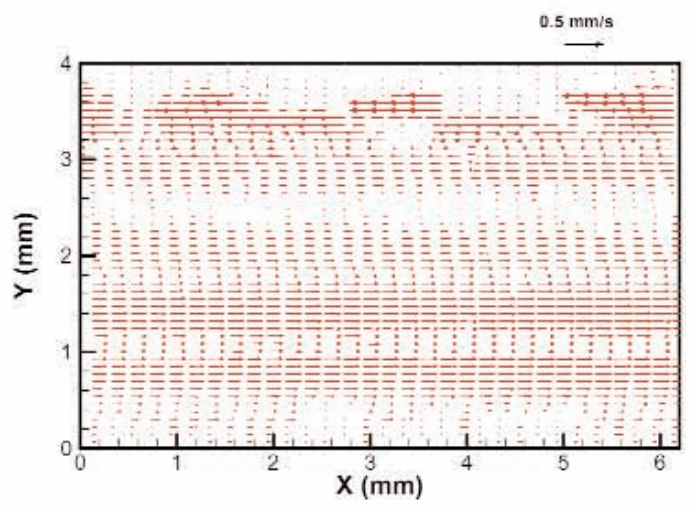

(f) $\mathrm{t}=0.333 \mathrm{sec}$

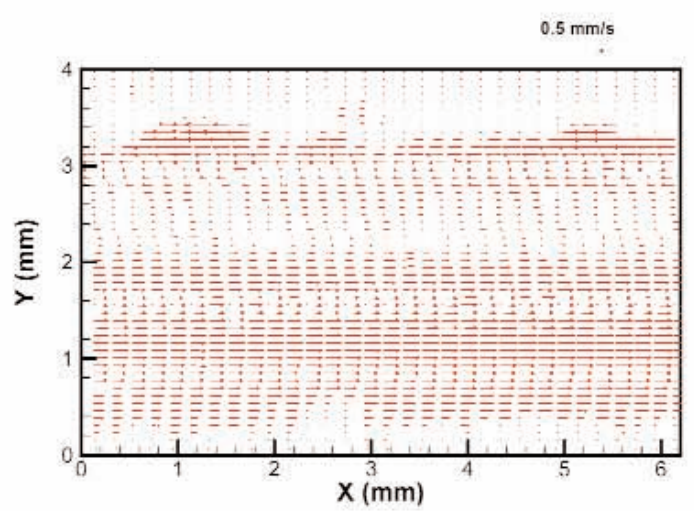

(h) $\mathrm{t}=1.000 \mathrm{sec}$

Fig. 8 The evolution of flow pattern at $\Delta T<\Delta T_{c l}$ 


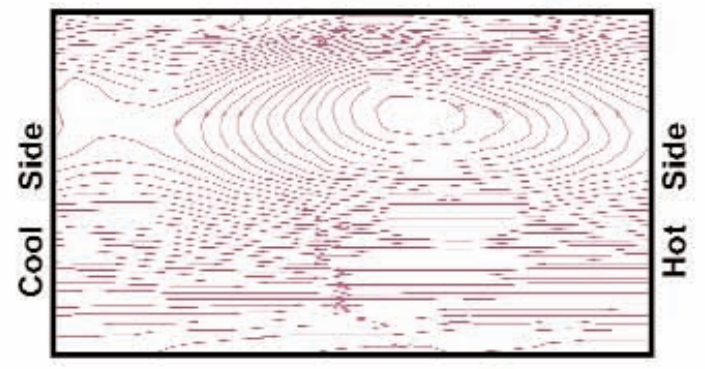

(a) $\mathrm{t}=0.000 \mathrm{sec}$

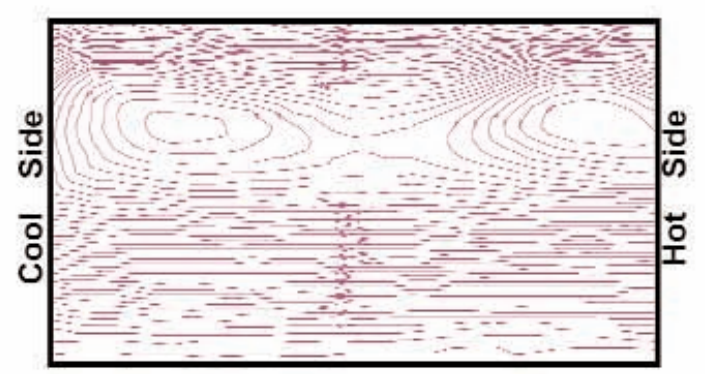

(c) $\mathrm{t}=0.667 \mathrm{sec}$

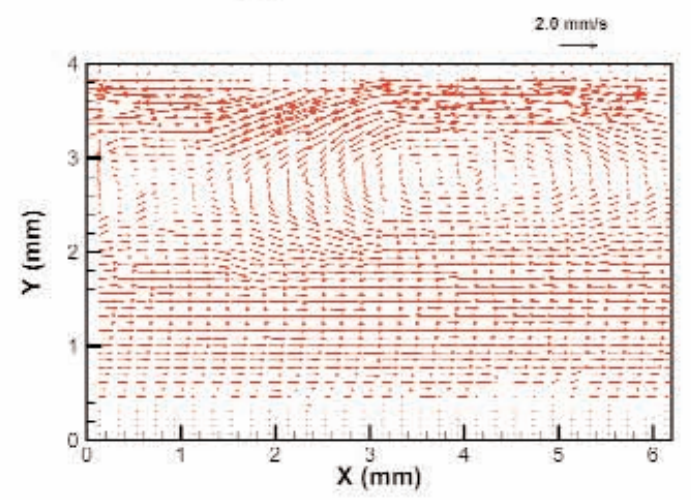

(e) $\mathrm{t}=0.000 \mathrm{sec}$

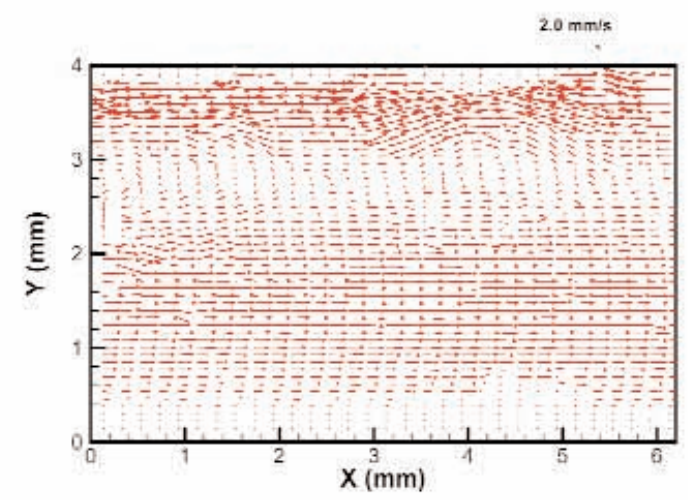

(g) $\mathrm{t}-0.667 \mathrm{sec}$

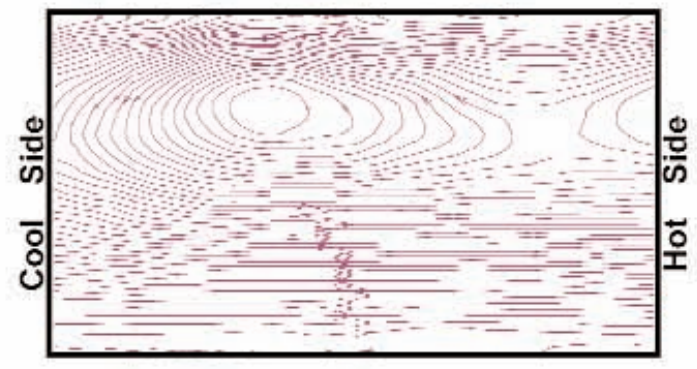

(b) $t=0,333 \mathrm{sec}$

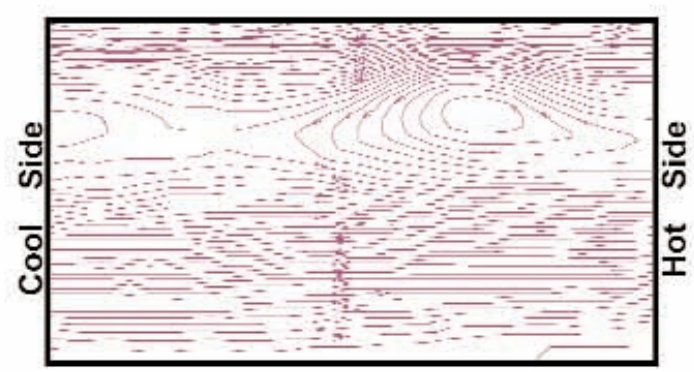

(d) $t=1.000 \mathrm{sec}$

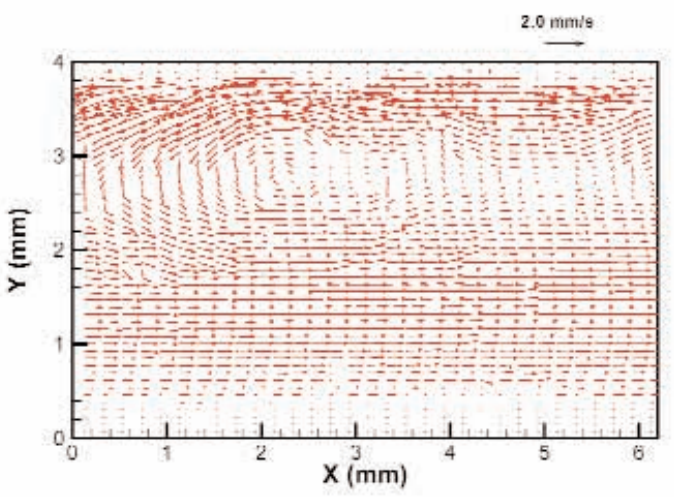

(f) $\mathrm{t}=0.333 \mathrm{sec}$

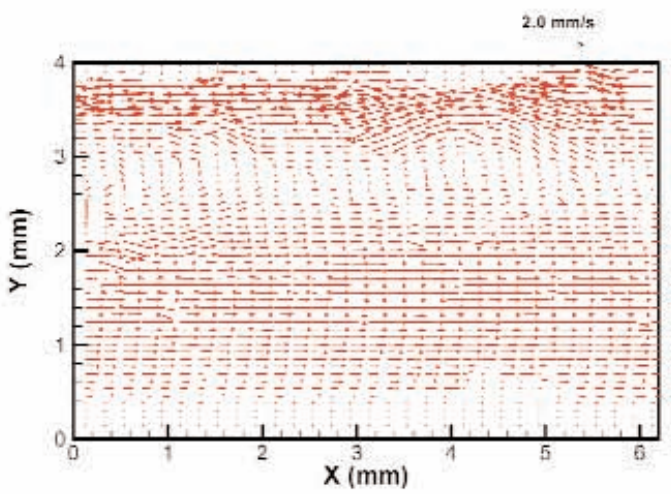

(h) $\mathrm{t}-1.000 \mathrm{sec}$

Fig. 9 The evolution of flow pattern at $\Delta T>\Delta T_{c 2}$ 
temperature gradient in the vertical direction; and the driving force for thermocapillary convection is the temperature gradient along the horizontal direction on the free surface of the liquid. Because the temperature in the upper part of the fluid layer is higher than that in the lower part, the direction of temperature gradient in the vertical direction is opposite to the direction of gravitational acceleration. Therefore, the fluid is steady-state with regard to the buoyancy. Though the effect of gravity can't be neglected, the convection is dominated mainly by the thermocapillary force at the early stage of the present experiment.

\section{Conclusion}

The PIV technique was adopted to observe the feature and the development of buoyant-thermocapillary convection introduced by the gradient of surface tension and the buoyancy. An optical diagnostic system consisting of a revised Michelson interferometer with image processor has been developed to study surface shapes in fluid convection. They are rather helpful and convenient in measuring flow patterns and surface deformation since they don't touch or disturb the liquid under observation. Temperature in the liquid was also measured with a thermocouple during the development of convection. A inerratic temperature oscillation was also detected although its amplitude is very small. Surface shapes and flow patterns are obtained quantitatively and their evolution were analyzed. With increasing temperature difference, the free surface present tilt, curve and wave gradually, and the flow pattern changes from steady to unstable. Both the surface shape and the flow pattern are quite different when the temperature difference $\Delta T$ exceeds the critical value $\Delta T_{c l}$. The profile of temperature oscillation is obtained and the characteristics of temperature oscillation are worked out. There are complicated relationships among temperature oscillation, velocity field, surface deformation and surface wave. The surface deformation is quite distinct in buoyant-thermocapillary convection. For understanding the mechanism of buoyant-thermocapillary convection, not only the hydrothermal wave instability but also the surface wave instability should be considered.

\section{Acknowledgements}

This work was supported by a grant from Knowledge Innovation Program of Chinese Academy of Sciences (KJCX2SW-L05, KSCX2 - SW - 322).

\section{References}

[1.] R. J. Riley, G. P. Neitzel, Instability of thermocapillary-buoyancy convection in shallow layers. Part 1. Characterization of steady and oscillatory instabilities, Fluid Mech. J. Fluid Mech. 1998, vol. 359, 143164.

[2.] J. Burguete, N. Mukolobwiez, F. Daviaud, N. Garnier, A. Chiffaudel, Buoyant thermocapillary instabilities in extended liquid layers subjected to a horizontal temperature gradient, Physics of Fluids, Vol. 13, No.10, 27732787.

[3.] Y. Kamotani, J. H. Lee, S. Ostrach, An experimental study of oscillatory thermocapillary convection in cylindrical containers, Phys. Fluids A, 1992, Vol. 4, No. 5, 955-962.

[4.] W. R. Hu, S. C. Xu, Microgravity Fluid Mechanics, Science press, China 1999.

[5.] W. R. Hu, H.T. You, Z. H. Cao, Free surface oscillation of thermal capillary convection in liquid bridge of half floating zone, Scientia Sinica A, 1992, 35, 1101.

[6.] J. Z. Shu, Y. L.Yao, H. Zhou, W. R. Hu, Experimental studies of free surface oscillation of a liquid bridge by optical diagnostics, Microgravity Science and Technology, 1994, 7, 83.

[7.] Z. H. Cao, J. C. Xie, Z. M. Tang, W. R. Hu, Experimental investigation of thermalcapillary convection in a half floating zone, Advances in Space Research, 1991, 11(7), 163

[8.] M. Hamed, J. M. Floryan, Marangoni convection. Part 1. A cavity with differentially heated sidewalls, J. Fluids, 2000, Vol. 405, 79-110.

[9.] M. Takeda, K. Mutoh, Fourier transform profilometry for the automatic measurement 3-D object shapes. Appl. Opt., 1983, 22(24):3977-3982.

[10.] T. R. Judge \& P. J. Bryanston-Cross, A Review of Phase Unwrapping Techniques in Fringe Analysis, Opt. \& Lasers in Eng., 1994, 199-239.

[11.] D. A. Nield, Surface tension and buoyancy effects in cellular convection, Journal of Fluid Mech., 1964, 19341. 